\title{
FENOMENOLOGÍA Y HERMENÉUTICA
}

\section{DANIEL HERRERA RESTREPO ${ }^{1}$}

Resumen: En este artículo se mostrará el punto de encuentro entre fenomenología y hermenéutica a partir de la visión husserliana de mundo de la vida. Se formularán, en forma de tesis, los tres aportes que Husserl ha dado a la actual hermenéutica: 1) El sentido y significado de un hecho, de una realidad o de una palabra están predeterminados por su horizonte de donación; 2) Lo presupuesto como "suelo" de toda experiencia y horizonte de todo "darse" con sentido, es el mundo de la vida cotidiana (Lebenswelt); 3) Todo comprender, científico o no científico, presupone una "precomprensión" del mundo, articulada de antemano lingüísticamente.

Palabras clave: mundo de la vida, horizonte de sentido, experiencia, comprensión, interpretación, lenguaje.

Abstract: In this article the encounter point will be shown between phenomenology and hermeneutics, starting from Husserl's vision of world of the life. In thesis form, the three contributions that Husserl has given to the current hermeneutics will be formulated: 1) The sense and meaning of a fact, of a reality or of a word are predetermined by its donation horizon; 2) What is presupposed as "ground" of all experience and as horizon of whatever is given with sense, is the world of the daily life (Lebenswelt); 3) Every understanding, scientific or not scientific, presupposes a "pre-understanding" of the world, prelinguistically articulated.

Key words: world of the life, sense horizon, experience, understanding, interpretation, language.

Heidegger y Gadamer definieron la hemenéutica como la autocomprensión, la cual no sería otra cosa que la comprensión del propio ser como ser en el mundo; pero, ¿qué es el mundo del cual ellos nos hablan? Es en la interpretación del sentido del mundo que está presente como uno de los aportes más significativos de la fenomenología del último Hussenl, el Hussenl del mundo de la vida.

Los hermeneutas del presente se sienten deudores frente a la fenomenología husserliana. La razón es simple: si su interés recae sobre el problema de la interpretación del sentido del mundo dado, la fenomenología es la filosofía de la experiencia a partir de la cual el mundo recibe un sentido.

Quisiera dedicar esta exposición a esclarecer la visión husserliana del mundo de la vida. Inicialmente formularé, en forma de tesis, los tres aportes que Husserl

\footnotetext{
${ }^{1}$ Facultad de Filos ofía Univ ersidad Santo Tomás 
ha dado a la actual hemenéutica, aportes que han sido enriquecidos, sin duda alguna, por los hemeneutas. Los enunciaré en términos de tesis:

1. $^{\circ}$ El sentido y significado de un hecho, de una realidad o de una palabra están predeterminados por su horizonte de donación. En contra de la tesis neopositivista, se afima que el sentido de los hechos y de las palabras no se agota en la singularidad concreta, sino que remite a un sistema interrelacional entre objetos y palabras que comparten un sentido unitario.

$2^{\circ}$. Lo presupuesto como "suelo" de toda experiencia y horizonte de todo "darse" con sentido, es el mundo de la vida cotidiana (Lebenswelt). Esto significa: el mundo es la instancia trascendental (condición de posibilidad) a la que toda experiencia singular remite y que en toda experiencia es tá implicado. $\mathrm{O}$, con otras palabras: el mundo de la vida es el tan buscado "a priori universal concreto" del conocer y del comportarse.

$3^{\circ}$. Todo comprender, científico o no científico, presupone una "precomprensión" del mundo, articulada de antemano lingüísticamente. Esto significa que el mundo de la vida lo experimentamos lingüís ticamente interpretado, y por lo mismo, implica una intersubjetividad que ha constituido el sentido del mundo, de un mundo que, por consiguiente, se nos da poseyendo de antemano una "interpretación pública".

Antes de exponer cada una de estas tesis, quisiera hacer dos observaciones:

Todo el esfuerzo de Husserl, a lo largo de su vida, estuvo dirigido a aclarar una intuición tenida en 1897: existe una correlación entre el hombre y el mundo. Este esfuerzo implicó todo un proceso, cuyas etapas pueden recibir diversas denominaciones. Una de ellas, la más conocida entre nosotros, es la idealista de Ideas (1913). Léase, por ejemplo, el parágrafo 49. Sólo a partir de 1920 Husserl logra colocarse en la misma correlación y no en los términos de ella, lo que le permitió superar sus posiciones realistas de las Investigaciones Lógicas de 1900 y las posiciones idealistas de Ideas, para hacer de la fenomenología una filosofía de la experiencia humana.

No es de mi interés discutir en detalle la influencia de Husserl en la hermenéutica actual: honestamente no estoy en capacidad para ello y, por otra parte, dentro de la actual hemenéutica se dan divers as tendencias, cada una de las cuales se remite a Husserl de acuerdo con sus propósitos. Recordemos rápidamente algunas de es tas tendencias:

Esbozo de las principales tendencias de la hermenéutica contemporánea

a. Hay una Hermenéutica Metódica, heredada de Dilthey, que ante los éxitos de las llamadas ciencias de la naturaleza, alcanzados gracias a su universalidad y objetividad, se interroga sobre las condiciones de posibilidad epistémicas y metodológicas de las llamadas ciencias humanas para que su interpretación del 
mundo alcance, igualmente, "universalidad y objetividad". Esta tendencia cree, ingenuamente, que en este mundo se puede dar la pretendida distancia entre sujeto y objeto que se da en las ciencias de la naturaleza.

b. Tenemos una Hermenéutica Ontológica, aquélla de un Heidegger o de un Gadamer, para quienes la experiencia se configura en el lenguaje. Interesados en el ser, tras largos análisis, llegan a la conclusión que el único ser que nos es accesible es el que se nos revela en el lenguaje. Olvidan, sin embargo, que el lenguaje también es un medio de dominio y de poder; que el lenguaje puede ser el lugar de la verdad y de la comunicación correcta, pero también de la no verdad y de la comunicación distorsionada. Los actos del habla no son sólo lingüísticos sino comunicativos, lo que supone no jugar solitariamente un juego lingüístico, sino someter el habla a las reglas cuyo cumplimiento corresponde siempre el interlocutor, al menos ideal, con los mismos derechos del hablante.

c. Otra tendencia es la Hemenéutica Semiológica de Ricoeur, en nuestro entender el francés que más ha conocido profundamente a Husserl. Su interés, sin embargo, es igualmente ontológico, como el de Heidegger y Gadamer. Pero, como buen francés que no renuncia al espíritu cartesiano, está orientado a la comprensión del yo. Para lograrlo, sigue el largo camino del anális is de las zonas simbólicas producidas por el hombre: sueños, mitos, ritos, metáforas, etc. Ricoeur ha puesto de presente cómo el lenguaje simbólico es multívoco y, como tal, lo más opuesto al lenguaje unívoco de las ciencias. Sólo a través de análisis semiológicos muy detallados de dicho lenguaje podemos llegar a saber lo que somos.

d. Finalmente citemos la Hermenéutica Crítica de Jürgen Habemas o de Kart Otto Apel, quienes parten de la convicción de que la posibilidad del conocimiento se fundamenta en los intereses de la vida cotidiana. Para quienes se interesan en el mundo de lo social, se trata del interés de la emancipación de los dominados, emancipación que presupone una crítica de las ideologías que sostienen a los dominadores: es necesario develar el sentido de estas ideologías para posibilitar la comunicación y convergencia entre las diversas perspectivas de cada uno de los mundos cotidianos en pro de la convivencia, pues el criterio de validez de una norma sólo puede ser el consenso ciudadano. Este consenso es posible si el oyente entiende al hablante, lo cree veraz, acepta la verdad del contenido proposicional y si, finalmente, considera correcta la noma aprobada.

Como hemos dicho, cada una de estas tendencias hermenéuticas se remite a Husserl de acuerdo con sus intereses. Todas ellas, sin embargo, reconocen su deuda con las tres tes is que hemos enunciado, tesis que expresan el esfuerzo de Husserl por superar el dogmatismo de una visión objetivista del saber y de la acción humanos y su lucha contra las manifestaciones de aquel dogmatismo en la fijación del estatuto de cientificidad de las ciencias socio-culturales y del ejercicio ético-político. A lo largo de su vida Husserl buscó el a priori concreto o esfera precategorial que, como instancia trascendental, permitiría fijar las condiciones de posibilidad de la ciencia, de la acción y del lenguaje. Creyó estar cerca de este a 
priori después de 1920 con su visión del mundo de la vida, cuya explicitación apunta no sólo al rescate del sujeto social de la ciencia y de la historia, sino sobre todo a fundamentar toda actividad humana, incluyendo la científica, sobre un soporte de sentido y finalidad que permitiera superar la crisis del hombre en la época de la civilización técnico-científica. Es esta intencionalidad básica del esfuerzo huserliano la que coincide con la intencionalidad fundamental de todos los hermeneutas del siglo XX.

Pero analicemos más detalladamente las tres tesis husserlianas que hemos enunciado.

\section{Principales aportes de la fenomenología de E. Husserl a la hemenéutica}

Los principales aportes de la fenomenología huss erliana a la hemenéutica contem poránea se pueden resumir en las siguientes tesis:

Primera. El sentido y significado de un hecho, de una realidad o de una palabra están predeteminados por su horizonte de donación.

Así, en contra de la tesis neopositivista, se afima que el sentido de los hechos y de las palabras no se agota en la singularidad concreta, sino que remite a un sistema interrelacional entre objetos y palabras que comparten un sentido unitario.

Segunda. Lo presupuesto como suelo de toda experiencia y horizonte de todo darse con sentido, es el mundo de la vida cotidiana. Esto significa que el mundo es la instancia trascendental (léase condición de posibilidad) a la que toda experiencia singular remite y que en toda experiencia está coimplicado. $\mathrm{O}$, en otras palabras, e! mundo de la vida es el tan buscado a priori universal concreto del conocer y del ser.

Tercera. Todo comprender, científico o no científico, presupone una precomprensión del mundo, articulada de antemano lingüísticamente. Esto significa que el mundo de la vida lo experimentam os lingüís ticamente interpretado, por lo mismo implica necesariamente una intersubjetividad que ha constituido el sentido del mundo, en un mundo que, por consiguiente, se nos da proyectando de antemano una interpretación púb lica.

Primera: el horizonte como estructura de toda posible experiencia.

El tema del "horizonte" es uno de los primeros que más inquietó a Husserl. Él dice relación al viejo problema del "cómo" del conocimiento humano y ofrece una nueva alternativa frente a las conocidas del positivismo-idealismo, del empirismoaprionsmo. Cuando queremos interpretar un acontecimiento (v.g., el descubrimiento de América), o una palabra (v.g., "descubrimiento"), o un dato (el do de una melodía), no nos podemos quedar en la singularidad de los mismos como piensa el objetivismo. Acontecimientos, palabras y datos remiten a un sistema interrelacional entre objetos o palabras, que comparten un sentido 
unitario. El término horizonte expresa esta perspectiva global de sentido, presupuesta y no necesariamente explicitada, que predetemina el sentido y significado de cualquier hecho o palabra ubicado en ella. Es este horizonte el que aporta el sentido en el "que el objeto se convierte en tema... Todo lo dado, en cuanto dado, remite a un plus ultra de símismo, al horizonte de donación"2.

Lo anterior significa que para Husserl toda experiencia posee una estructura de horizonte u estructura horizontal. La percepción de lo singular tiene lugar en foma de secuencia temporal en la que cada experiencia actúa de elemento clarificador de una experiencia anterior o susceptible de ser clarificada por otra posterior, pues toda experiencia implica una preciencia, un saber con antelación o un saber en relación que pertenece a la estructura del mismo experimentar. El horizonte hace referencia, precis am ente, a es a totalidad de lo percibido o perceptible en cada uno de los actos cognitivos particulares.

En concreto, esto significa que, "desde el punto de vista de la toma de conciencia, lo percibido no termina allí donde termina la percepción"3, los límites de la percepción y los límites de la experiencia no coinciden: la experiencia está vinculada a un sistema de relaciones espaciales o temporales, que constituyen un contexto de sentido, en donde se dan cita lo particular determinado con lo general indeteminado. En este horizonte cada dato proyecta una luz sobre el resto de los componentes de la totalidad y recibe de ellos, recíprocamente, clarificación. De aquí que la reducción empirista del conocimiento y del lenguaje achica injustamente el campo del saber. Toda experiencia implica una preciencia, un "saber con antelación" (Vorwissen) y una conciencia o "saber en relación" (Mitwissen) que pertenecen a la estructura del mismo experimentar. Este saber con otras cosas y este saber con antelación es lo que pretende expresar el término horizonte. Experimentar es conocer en perspectiva los objetos y las palabras acompañadas de las connotaciones y referencias que le son propios; la interpretación y comprensión de la evidencia y verdad de cualquier dato o palabra necesita, dada su inserción en un contexto de sentido, "mantener siempre ante los ojos que en el horizonte de experiencia se encuentra inseparablemente inscrita cualquier operación de experiencia". Añadamos otros pasajes de Husserl: "Toda vivencia actual, tiene necesariamente su horizonte del tiempo inmediatamente anterior y posterior". Pasado y futuro aparecen implicados en el ahora.

La corriente de vivencias constituye una unidad y su forma se proyecta "por todas las vivencias del yo puro". Con antelación a cualquier actividad cognoscitiva, los objetos "se encuentran a nuestra disposición, en calidad de objetos válidos para nosotros antes del conocimiento de los mismos. El sentirse afectados por ellos es previo a su captación conceptual. Afectación que no tiene lugar de modo aislado sino como acto, que surge en un contexto y bajo un interés

\footnotetext{
${ }^{2}$ Cfr. Brand: Welt, Ich und Zeit. Nijhoff, La Haya, 1955.

${ }^{3}$ Erste Philosophie II. Nijhoff, La Haya, 1958; p. 147; Erfahrung und Urteil. Editorial Academia dePraga,P raga, 1939; p. 27.

${ }^{4}$ Ibidem, p. 39. 
determinado... Esa circunstancia en la que el objeto viene dada es el ámbito de la predonación pasiva"5.

Este modo de saber define los contenidos a que se refieren las actitudes llamadas "personales" en contraposición a las "naturales", y conforma el campo de los acontecimientos histórico-culturales o de los valores éticos, en donde las intenciones y motivaciones del sujeto desempeñan un rol prioritario. El sentido de ese mundo, y dentro de él, del hecho de las ciencias modemas, como un acontecimiento histórico más, vienen dados en el horizonte en el que aparecen ${ }^{6}$.

Empero, Husserl añade una serie de precisiones. El horizonte es una perspectiva abierta a ulteriores deteminaciones en cuanto ámbito de experiencias posibles, conexas en el espacio y en el tiempo con una experiencia concreta. En cuanto perspectiva abierta, el horizonte se desplaza al paso de quien en él se mueve. Gadamer precisa esta idea: el horizonte de la historia cambia en correlación a como cambia la conciencia histórica y modifica con su cambio la reconstrucción del pasado desde la conciencia del presente. Desde el punto de vista del objeto, Husserl distingue un 'horizonte interno' constituido por las potencialidades no explicitadas de la experiencia en curso, pero susceptibles de explicitación a partir de la misma y, el 'horizonte externo', integrado por los objetos que acompañan a la cosa y sobre los que no versa aquella experiencia pero que son susceptibles de ser experimentados por entrar a formar parte del horizonte global de sentido en el que la percepción tiene lugar ${ }^{7}$.

El vínculo entre experiencia y horizonte no es nuevo. La relación parte-todo, singular-universal, que el concepto de horizonte trata de expresar, se encuentra formulada de múltiples formas en la tradición. Podríamos retroceder a Spinoza o Leibniz. Contentémonos con mencionar a Kant y a Hegel.

Para Kant, horizonte, en sentido epistemológico, significa la capacidad de una potencia humana en un campo específico de la percepción.

En este sentido el horizonte fija las posibilidades y, a la vez, los limites del conocimiento humano, y puede referirse a un campo epistemológico, ético o estético, según que delimite el área de intereses y de la acción posible y de la razón teórica, del sentido del gusto o de la razón práctica. Con ello el término horizonte, responde a la pregunta sobre "qué puede y cómo puede el hombre saber, gus tar o practicar" (cfr. Logik, passim).

En Hegel el concepto tiene un sentido ontológico: hace referencia a la totalidad en cuyo devenir dialéctico tiene su ubicación lo particular, recibiendo de aquélla, ser, verdad y sentido. En el siglo XX citemos, en primer lugar, al his toricismo de

\footnotetext{
${ }^{5}$ Ibidem, págs. 23-24; Ideen Zur Einer Reinen Phänomenologie und Phänomenologischen Philosophie III, Nijhoff, La Haya, 1952, págs. 184-185.

${ }^{6}$ Ideen Zur Einer Reinen Phänomenologie und Phänomenologischen Philosophie II, Nijhoff, La Haya, 1952, págs. 173208,367 ss.; Krisis págs. 153-296, 306

${ }^{7}$ Verdad y Método. Ed. Sígueme, Salamanca, 1977, págs. 372-447. 
Dilthey: el témino horizonte hace referencia a la temporalidad y a los contextos históricos del hombre: el horizonte de una época es el sistema socio-cultural de la misma en el que el pens amiento y la praxis encuentran situación y sentido.

En Heidegger "horizonte" recupera el sentido ontológico al significar la constitución trascendental del seren-el-mundo del hombre. "Mundo en cuanto horizonte" significa un proyecto global de sentido en donde se inscriben las diversas posibilidades o proyectos concretos de existencia: el horizonte es la realidad predonada que condiciona la realización del existir en cuanto que éste proyecta sus posibilidades en una totalidad predonada y condicionante. Tal totalidad es el mundo en cuanto horizonte de posibilidades. El ser-en-el-mundo, en cuanto es tructura del existir, significa que el hombre presupone el mundo como horizonte de su autocomprensión e interpretación. El mundo es, por lo mismo, condición de posibilidad de la comprensión de Dasein.

Husserl utiliza la categoría "horizonte" con un significado equivalente a la fórmula "situación hemenéutica" de Gadamer. De igual manera que una situación hermenéutica está determinada por preconceptos que el intérprete aporta, el horizonte es tá integrado por el ámbito espacio-temporal que rodea a la experiencia concreta. Comprender un texto o interpretar un acontecimiento significa haber propuesto preguntas y respuestas interrelacionadas por un nexo de sentido, que solamente viene dado por el horizonte en el cual aquellas se plantean ${ }^{8}$, pues el hombre que piensa, habla o investiga se encuentra en un mundo dado previamente, del que forma parte, del mundo de la vida, de la historia, de los valores, que constituye el lugar donde se comprende a símismo ya partir del cual propone preguntas y respuestas. En este espacio histórico-cultural es donde tienen lugar los fenómenos que llamamos ciencia, lenguaje, comunicación. Husserl lo denomina Unwelt (mundo circundante) al ser este espacio condición de posibilidad de la experiencia de lo concreto, el intérprete se enfrenta al problema hermenéutico como cuestión previa en tomo a ese mundo y su sentido, dado que es el suelo donde el hombre ejerce su actividad científica, lingüística o comunicativa.

El concepto de horizonte marca de esta manera un abismo entre la fenomenología y la hermenéutica por una parte, y las explicaciones atomistas del empirismo y de sus derivaciones por otra. La soledad que afecta a los hechos y a las palabras es 1a soledad que los afecta en cuanto fenómenos reducidos a objetos y no en cuanto a fenómenos vividos en y por el sujeto humano. La interobjetividad de las cosas y la intersubjetividad de los actos de la conciencia son estructuras de la experiencia humana. El "saber con antelación" (vorwissen) y el "saber en relación" (mitwissen) acompañan a todo saber. Tal situación tiene lugar de modo eminente en los contextos de finalidad que motivan las acciones humanas y en los nexos de sentido que orientan los acontecimientos históricoculturales.

\footnotetext{
${ }^{8}$ Verdad y Método, págs. 372,447. 
Lo mismo acontece en el mundo del lenguaje y de la comunicación. Explicar atomísticamente el lenguaje o interpretar los actos de comunicación de modo aislado, presupone desarraigar el lenguaje del suelo sobre el que los hechos humanos tienen as entamiento o, como dice Heidegger, acontecimiento (Ereignis); presupone, por lo mismo, alejarse de las cosas mismas para adentrarse en el mundo abstracto de la formalización e idealización físico-matemática que caracteriza al objetivismo de la ciencia moderna.

Segunda: el mundo de la vida (Lebenswelt) como horizonte universal de la experiencia

Para Husserl el concepto de horizonte está vinculado con la idea de "mundo": toda experiencia singular se da en el mundo, en calidad de horizonte universal. El mundo es lo presupuesto como suelo de toda experiencia y como horizonte de todo acontecimiento. El mundo aparece como la instancia trascendental a la que toda experiencia singular remite, pues en cuanto horizonte universal, ejerce la función de plataforma global de sentido sobre la que se asientan las diversas perspectivas en las que el hombre percibe los objetos. El tema del horizonte de la experiencia nos conduce así al tema del mundo en los diferentes significados que puede tener: mundo como naturaleza, mundo como historia, mundo como sociedad, mundo del lenguaje, mundo de la ciencia, mundo universitario, etc. Y, más allá de tales mundos especiales, al mundo en general, carente de especificación. Este mundo es el lugar del ser y del sentido originarios. Es, en términos de Husserl, el "a prior concreto" al que remite toda experiencia y donde tienen lugar las donaciones originarias de sentido.

Empero,, el concepto fenomenológico de mundo se contrapone al concepto fís ico-matemático galileano: él es tá vinculado a la his toria y a la subjetividad. Para Husserl el concepto galileano del mundo como extensión es lo más vacío y lo más pobre. Hussen utiliza diversas fórmulas para designar el mundo de la vida. "Mundo vivo del espacio y del tiempo", "mundo circundante personal", etc. En sus últimos años las diversas fómulas son sustituidas por el témino "mundo de la vida" para indicar, de manera más clara, que él es el ámbito de las evidencias

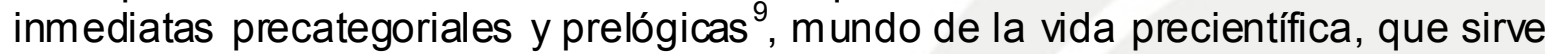
de soporte a toda actividad humana. La contraposición de "mundo de las ciencias y mundo de la vida" se puede comprender mejor a la luz del modo como se constituye el mundo especializado y de las relaciones que existen entre éste y la Lebenswelt. Un mundo especializado es constituido a partir de una idea finalizante, la cual res tringe el ámbito de la teoría pura a un "horizonte interesado". La actitud del espectador desinteresado que caracteriza al fenomenólogo se toma en actitud interesada que achica el horizonte de interpretación. Mientras la Lebenswelt posee un sentido universal que, implícitamente, se complica con los mundos derivados, éstos reducen su área de interés a una finalidad particular.

${ }^{9}$ Krisis, págs. 141, 145, 461, 494-495. 
Es lo que acontece, por ejemplo, con el mundo de la ciencia, que se constituye como mundo particularizado bajo la idea rectora de un ser objetivo en sí, deteminable matemáticamente. La Lebenswelt, por el contrario, es lo dado con antelación a toda deteminación o concreción del sentido. Intercambiar o sustituir el mundo de la vida por un mundo particular significa, por consiguiente, tomar la parte por el todo, reducir el concepto de realidad ${ }^{10}$.

El mundo de la vida es un conglomerado sociocultural integrado por opciones de valor, experiencias subjetivas y sedimentos históricos; es el mundo donde se nace y se muere, donde se hereda una tradición cultural, donde se comunica un lenguaje, donde se vive intersubjetivamente. Es el mundo de la cotidianidad, en cuyo horizonte nos encuadramos para orientarnos y es, a la vez, tejido de las relaciones sociales; es el mundo del trabajo, de la familia, de los usos y las costumbres. Un mundo de personas y de cosas que están en relación esencial conmigo y que constituyen mi mundo. "Es el mundo de la existencia concreta precientífica donde el hombre se instala, actúa, construye proyectos y se realiza como científico, como político, como creyente. Es el mundo de la experiencia cotidiana donde el yo que filosofa posee una existencia consciente y en el que se inscriben las ciencias y los científicos. En ese mundo somos objetos entre los objetos y en el polo opuesto, sujetos egológicos teleológicamente referidos a ese mundo como quienes lo experimentan, valoran, se preocupan. Un reino, en fin, de valores y metas, que no es sus tituible por manifestación parcial alguna del mismo, como pretende el objetivismo científico, sino que subyace como sustrato englobante de todo acontecer y de cualquier obrar."11

El mundo de la vida, en cuanto horizonte universal en el que hacen aparición los objetos, es una estructura predada y universal de la conciencia. Es esta una de las principales contribuciones de Husserl. Contra el positivismo objetivis ta se recupera una dimensión básica de la epistemología, a saber, que el conocimiento de lo singular acontece en una totalidad originaria de sentido, en una experiencia del mundo de carácter prerracional, delimitada en el espacio, culturalmente acuñada por la historia y decantada en un sistema lingüístico. El mundo de la vida, como horizonte, expresa aquella totalidad percibida de modo no explícito, presupuesta aunque no tematizada que condiciona y determina la verdad del sentido de cada cosa en ella enmarcada. Toda toma de posición presupone un conjunto de evidencias como la de que el mundo existe y que cualquier modificación de una experiencia presupone un mundo como horizonte de seresvalores aceptado, en y des de el que se opera ${ }^{12}$.

"Vivir, -dice Husserl- es vivir en la certeza del mundo". Mundo es, por consiguiente, no universo de las cosas o enunciado de las ciencias, sino aquel ámbito en cuya interioridad vivimos, cuya realidad presuponemos antes de que construyamos ciencia o planteemos preguntas filosóficas. Porque el científico

\footnotetext{
${ }^{10}$ Ibídem, págs. 459-462.

${ }^{11}$ Ibidem, págs. 107, 461-484.

${ }^{12}$ Erfahrung und Urteil, págs. 38 ss., 45 ss. 
antes de formalizar sus experiencias físicas mediante las matemáticas o el hermeneuta antes de interpretar los productos culturales, son hombres ubicados en el mundo de la vida cotidiana.

Los mundos derivados y la constitución del sentido de los mismos remite, por lo mismo, al mundo de la vida como al a priori precategorial concreto. Si queremos aclarar la génesis y el sentido de las evidencias derivadas, tenemos que recuperar este ámbito precategorial del mundo de la vida ${ }^{13}$, el mundo en el que nosotros ya vivimos y que constituye el suelo de todas nuestras praxis, un mundo históricamente sedimentado e integrado por operaciones intersubjetivas e intencionales, que es tanto como afimar la existencia de una teleología. Explicitar este mundo implica, como dice Husserl, "despejar la historia del mismo mundo" en el que el hombre se encuentra con antelación a su actividad cientíica y lingüística. Para esto, según Husserl, son posibles dos caminos: a) retrotraer el mundo de las ciencias al mundo de la vida. b) remitir las actividades del mismo mundo de la vida a las operaciones constituyentes del sujeto, de donde el mismo mundo de la vida surge. Este retroceso es transitable por un doble camino: el de la historia, a través del cual efectuamos un seguimiento de la constitución temporal del mundo de la ciencia y su lenguaje y el de la psicología, analizando genéticamente los actos de la conciencia por los que tanto la ciencia como su lenguaje han llegado a ser lo que son ${ }^{14}$.

El retorno al mundo de la vida como mundo histórico y a la subjetividad como instancia constituyente de sentido presupone tomar conciencia del camino recorrido por la humanidad en la modernidad. El recorrido de este camino, según Husserl, lo podemos resumir así: en la génesis del mundo simbólico de la matemática tiene lugar un proceso de idealización y formalización en el que a partir de intuiciones empíricas habidas en el mundo precategorial se genera un universo de símbolos y signos con lo que se pretende expresar la racionalidad del universo. Las idealizaciones de los datos intuitivos distancian el lenguaje científico de la realidad concreta de donde se partió. La ciencia modema convierte en materia de su reflexión a un mundo de formalidades surgido en el proceso de idealización y lo que se originó como reflexión sobre las experiencias intuitivas del mundo se transformó en un saber sobre entes ideales objetivados que han perdido su vinculación con el mundo de la vida en cuanto mundo de las donaciones subjetivas de sentido. El universo de los símbolos matemáticos pasa a ser tenido en cuenta como el mundo real de los objetos y se toma por realidad aquello que sólo es un método ${ }^{15}$.

La fenomenología de Husserl es una acusación contra el neopositivismo, la cual se podría enunciar de la siguiente forma: el modelo científico y lingüístico del neopositivismo no es un modelo ni basado en, ni fiel a la experiencia. Se trata de un universo de entes formales generados en un proceso de idealización que ha

\footnotetext{
${ }^{13}$ Ibídem, págs. 21, 38-39.

${ }^{14}$ Ibidem, págs. 46 ss.

${ }^{15}$ Ibidem, ps. 46 ss. 
olvidado de dónde y para qué surgieron. La físico-matemática no se ha percatado de que su concepto de experiencia es el resultado de una formalización previa impuesta por la abstracción matemática.

El mundo donde se sitúa la labor científica es el mundo galileano-cartesiano del espacio exacto de la geometría y del tiempo exacto de la aritmética; un tiempo y un espacio que tienen poco que ver con el mundo histórico del sujeto y con el mundo cotidiano de la vida. Al hablar de experiencia en la físico-matemática se olvida que los procesos epistemológicos son actos de un sujeto que actúa según un sentido predonado en el mundo de la vida y que opera con unos supuestos percibidos en el ámbito precategorial: el concepto de experiencia es mucho más amplio que el profesado por la físico-matemática; $y$, el concepto neoempirista del saber opera con un concepto unilateral del mundo más allá del cual tienen lugar la experiencia precategorial, el lenguaje cotidiano y el sentido del mundo en el que el hombre mismo como hombre está instalado.

Tercera: el mundo de la vida es experimentado como mundo lingüísticamente interpretado

Bien conocido es el papel que juega el lenguaje en los hermeneutas. Gadamer decía que "en el lenguaje se basa el que los hombres tengan mundo". Husserl, por su parte, ya había sostenido en Experiencia y Juicio que el mundo de la vida se nos da a través de la tradición, del aprendizaje, de la comunicación, en una palabra, a través del lenguaje. De esta manera asentó uno de los pilares de la hermenéutica: nuestro acceso a la realidad está mediatizado por el lenguaje. Gadamer siguiendo a Husserl sostendrá, en contra de Habermas, que la comprensión que tenemos de la realidad, antes que estar determinada por relaciones de producción o por la pertenencia a una determinada clase social, está determinada por el universo lingüístico en el que estamos insertos. Antes que estar deteminado por un interés, nuestro conocimiento está determinado por la pertenencia a una tradición y a un lenguaje ${ }^{16}$. El presente viviente, individual 0 colectivo, sólo es experimentable porque en el lenguaje se ha sedimentado la experiencia pasada, la cual constituye factor deteminante de la existencia del horizonte que posibilita, como lo hemos visto, toda experiencia.

Nos encontramos actualmente ante tres visiones del lenguaje que podríamos simplificar de la siguiente manera: la del empirismo positivista (cultura sajona), la del idealismo humanista (cultura centroeuropea) y la de la dialéctica, que pretende mediar entre las dos primeras, tomando elementos de ambas en una teoría global de la sociedad. ¿Se podrían personalizar en Wittgenstein, Gadamer, Habermas? ¿Se podrían adscribir a tres mundos con sus correspondientes saberes: el científico-técnico, el humanista-literario y el socio-político? ¿Se corresponderían al pasaje de Habermas en el que tipifica los saberes a partir del interés que los orienta? Recordémoslo: "En el ejercicio de las ciencias empírico-analíticas interviene un interés técnico del conocimiento; en el ejercicio de las ciencias

\footnotetext{
${ }^{16}$ Verdad y Método, págs. 547 ss. 
histórico-hermenéuticas interviene un interés práctico del conocimiento y en el ejercicio de las ciencias orientadas hacia la crítica interviene un interés emancipatorio del conocimiento".

La situación anterior parece decimos que la aspiración del neopositivismo de lograr una ciencia unificada ha quedado de lado. A la luz del esquema husserliano para la interpretación del pensamiento modemo, la filosofía, hoy en día para tratar el tema del lenguaje tiene la posibilidad de optar por el tipo de racionalidad que Galileo aplicó en la construcción de la físico-matemática. En es ta opción el hablar y comunicar serán considerados como meros hechos físicos localizados en un tiempo y un espacio físicos tratables con la metodología con que se construyó la fís ico-matemática y equiparable a como Comte intentó desarrollar una física social o el psicologismo una psico-física. Los pasos que habría que dar desde esta perspectiva estarían indicados por los términos matematización, formalización, tecnificación, deshumanización.

Otra opción posible sería la racionalidad que habilitada por Kant perduró en el proyecto husserliano. Aquí el lenguaje y la comunicación serían considerados como acontecimientos histórico-culturales, como valores ético-políticos no analizables ni valorables plenamente en téminos epistemológicos físicomatemáticos. Se trataría para Husserl de ver en ellos ingredientes fundamentales del "mundo histórico de la vida", y, por ello, materia apropiada para ser interpretada con una metodología hemenéutica-fenomenológica. Sería la única posibilidad para aclarar el lugar donde se constituye el sentido y, a partir de él, para ponerse en claro lo acontecido en el proceso de cientifización y tecnificación del lenguaje y de la comunicación.

Creo que los problemas con los que se enfrenta la actual hemenéutica, en buena parte fueron formulados por Platón. En el Cratilo no sólo encontramos la contraposición phýsis y nómos, o lo que es lo mismo, entre el lenguaje confinado al mundo deteminístico de la naturaleza y un lenguaje producido por el mundo humano de la libertad, sino con un lenguaje cuyo sentido y significado se vincula al acontecer del diálogo, en cuanto búsqueda del eidos, del sentido que se alberga en las palabras.

En la intersubjetividad, en el diálogo, el lenguaje no sólo se libera de la esclavitud del objeto, sino también de la arbitrariedad del sujeto. Entra a formar parte del acontecer histórico de los interlocutores, en cuanto miembros de una comunidad de dialogantes que comparten un mismo mundo de la vida, se entrecruzan palabras cuyo sentido y significado acontece al hilo del discurso. Esta inserción de la palabra en el mundo de la vida se perdió cuando la lógica aristotélica y posteriormente la estóica sometieron de nuevo la palabra a la servidumbre del objeto. La comunicación y la palabra fueron dominadas entonces por el deteminismo fatal del logos cósmico, en donde la única libertad reside en echarse resignadamente en los brazos del des tino. 
Este naturalismo lingüístico reaparece en la edad moderna cuando los pensadores ingleses del siglo XVII, fieles al principio empirista, "se afanaron por captar el factum" del lenguaje en su simple y sombría facticidad, sin referencia alguna a instancias ideales o metafísicas $\mathrm{y}$, mucho menos, a instancias del mundo de la vida. El lenguaje fue concebido como mero instrumento del conocimiento empírico. Por paradójico que parezca, esta servidumbre de la palabra al objeto, mediante la reducción de su función a un rol de signo, perduró hasta el neopositivismo contemporáneo, en donde el lenguaje pasa a ser mera representación o reflejo del mundo físico y de sus estructuras matemáticas ${ }^{17}$.

En la reacción romántico-idealis ta contra el modelo galileano-cartesiano opera tam bién una inflexión profunda en la concepción del lenguaje. Vale la pena llamar la atención sobre la coincidencia de fechas del surgimiento de la hemenéutica contemporánea de Schleiemacher y de los impulsos que, para la nueva concepción del lenguaje, proceden de la veta pietista de la Reforma, para la cual, el concepto del lenguaje es inseparable del acontecer histórico de la Palabra Divina. Finalmente, hay que llamar la atención sobre los paralelismos que se pueden establecer entre la comprensión romántico-idealista del lenguaje y el concepto organológico del acontecer histórico a cargo de la incipiente filosofía de la his toria. Nos encontramos ante síntomas de desazón causada por la irrupción del modelo epistemológico galileano en zonas tan humanistas como la filología, la historia o la religión. En este contexto Hamman, Herder o Humboldt tratan de liberar la comunicación humana de la cosificación y formalización fisicalista y a descubrir el espíritu del lenguaje y su energía creadora. El luterano Hamman insiste en que la razón es el lenguaje en el que se exterioriza la vida divina en la historia; Herder subraya el componente subjetivo; y, Humboldt descubre en el lenguaje una totalidad orgánica cuya función no se reduce a ser signo de las cosas objetivas, sino que posee más bien un sentido propio que es transferido a las cosas cuando éstas son significadas. El lenguaje, en este caso aparece como organismo viviente, mundo cultural histórico, producido y sedimentado en una tradición y del que el parlante forma parte con antelación al que surja el lenguaje formalizado. En este mundo de la vida cotidiana, el lenguaje no se reduce a un mero correlato y significante de unos hechos, sino que posee una unidad de sentido que viene dada por el sujeto mismo constituyente de aquel sentido. EI anális is del lenguaje se empobrece tremendamente cuando es realizado en términos de hechos atómicos, o proposiciones moleculares, desvinculado del horizonte de sentido del mundo histórico y humano al que pertenece.

En la segunda mitad de nuestra centuria algunos dogmas neoempiristas han perdido progresivamente vigencia. Citemos algunos: la correspondencia entre enunciado y hechos empíricos, el ideal de un lenguaje científico universal según el modelo físico-matemático, el criterio de verificabilidad, el confinamiento de los enunciados metafísicos al ámbito de lo "sin sentido", etc. Esto ha sido consecuencia de la toma de conciencia de que también bajo los enunciados de los saberes naturales, subyacen preocupaciones teóricas que condicionan el sentido

\footnotetext{
${ }^{17}$ Ibídem, págs. $21 \mathrm{ss.}$ 
de los mismos. El regreso de Husserl al mundo de la vida se corresponde con el esfuerzo de muchos analis tas del lenguaje en pro de un retorno al lenguaje natural ordinario, más allá del fomalismo anteriomente dominante. El mundo de la vida, tal como lo pensó Husserl, poco a poco se ha ido convirtiendo en el horizonte de interpretación del sentido y del significado de los diferentes modelos científicos lingüísticos. Recientes desarrollos del neopositivismo, por ejemplo, los de Austin, han acentuado esta tendencia al reconocer el pluralismo de lenguajes válidos: ético, estético, científico, etc., cuya función y sentido derivan del mundo del lenguaje cotidiano, de donde emergen. La inmediatez de los actos empíricos proclamada por el neoempirismo, no lo es tanto, puesto que ellos implican presupuestos no explicitados: cada enunciado ha de habérselas con un sujeto previamente constituido y dado por el mundo al que el sujeto es tá inscrito. Entre el mundo personal del científico y su mundo científico-lingüístico existe una vinculación esencial. Tal ya era la tesis de Husserl en Lógica Formal y Trascendental, en Experiencia y Juicio y en Crisis $^{18}$.

Husserl y Wittgenstein, cada uno a su manera, escenifican en la propia biografía este proceso histórico. Husserl tratando de ir más allá del sujeto, aterriza en el mundo de la vida. Wittgenstein encuentra el más allá del objeto en el lenguaje cotidiano y en sus juegos. Lo logra gracias a su evolución desde una teoría atomística de los signos y desde un concepto del lenguaje como copia de la realidad (Tractatus) hacia un interés por el lenguaje cotidiano de la vida, forma originaria del lenguaje de la que se derivan los lenguajes especializados, generando la pluralidad de los juegos lingü ísticos. Todos los lenguajes remiten, sin embargo, al lenguaje cotidiano de la vida y son igualmente legítimos: el lenguaje ideal ha perdido validez epistemológica. Por su parte, Husserl partiendo de su interés juvenil por las matemáticas y la lógica llega después de pasar dolorosamente por el añorado cielo del idealismo trascendental al mundo de la vida cotidiana como instancia donde la subjetividad no aparece como contrapuesta a la objetividad, pues en cuanto mundo his tórico-cultural aunque esté vinculado al sujeto está constituido por el sistema de correlaciones existentes entre sujetosujeto y sujeto-objeto. Este mundo es el verdadero a priori universal: todo hecho de conciencia, vivencia o palabra, se asienta sobre este mundo que en cuanto horizonte aporta y confiere sentido y significación.

La estructura del conocimiento no es la atomística prodamada por el neopositivismo, sino una estructura interrelacional que viene dada por la vinculación de los objetos entre sí y por los modos y actos de conciencia mediante los cuales llegan a ser relevantes para el sujeto.

No existe ni un sujeto puro ni un objeto puro. Todo objeto presupone un sujeto y todo sujeto presupone un objeto. Ambos, sujeto y objeto, están mediados por el mundo donde la objetividad y la subjetividad tienen lugar.

\footnotetext{
${ }^{18}$ Krisis, págs. $71-273,306,509$ ss; Idem II, págs. 183 ss. 
Para Husserl los hechos y las palabras previamente a sus usos especializados poseen un significado ya constituido en y por la vida cotidiana. El lenguaje forma parte del mundo de la vida de los parlantes.

Más allá de su sentido particular, la palabra se vincula al mundo de la vida, que es tanto como decir, a un mundo ya culturalmente comprendido y lingüísticamente interpretado. El mundo de la vida actúa de suelo de los mundos lingüísticos que los intereses del sujeto particularizan.

Pero toda diversificación lingüística presupone su horizonte global de comprensión que es precisamente lo que Husserl pretende expresar con la categoría Lebenswelt o mundo de la vida: horizonte de comprensión no explicitado, sino anónimamente presupuesto, substrato histórico constituido por tradiciones, factores culturales, valores éticos, sistema de correlaciones intencionales subjetivas.

Existe lenguaje y existen lenguajes. El lenguaje es componente de la condición histórico-cultural del hombre, experiencia precategorial y precientífica, ingrediente del mundo de la vida. Los lenguajes, en plural, son el fruto de los intereses particulares que definen los mundos particulares; pero siempre dando por supuesto el hecho trascendental del lenguaje, como mediador inevitable en el descubrimiento del mundo del sujeto, por el sujeto y para el sujeto.

Recordemos de nuevo las palabras de Gadamer: "en el lenguaje se basa el que los hombres tengan mundo".

Bogotá, abril de 2003 